\title{
A Developmental Shift from Positive to Negative Connectivity in Human Amygdala-Prefrontal Circuitry
}

\author{
Dylan G. Gee, ${ }^{1}$ Kathryn L. Humphreys, ${ }^{1}$ Jessica Flannery, ${ }^{1}$ Bonnie Goff, ${ }^{1}$ Eva H. Telzer, ${ }^{1}$ Mor Shapiro, ${ }^{1}$ Todd A. Hare, ${ }^{3}$ \\ Susan Y. Bookheimer, ${ }^{1,2}$ and Nim Tottenham ${ }^{1}$ \\ Departments of ${ }^{1}$ Psychology and ${ }^{2}$ Psychiatry and Biobehavioral Services, University of California, Los Angeles, Los Angeles, California 90095, and \\ ${ }^{3}$ Department of Economics, University of Zurich, CH-8006 Zurich, Switzerland
}

Recent human imaging and animal studies highlight the importance of frontoamygdala circuitry in the regulation of emotional behavior and its disruption in anxiety-related disorders. Although tracing studies have suggested changes in amygdala-cortical connectivity through the adolescent period in rodents, less is known about the reciprocal connections within this circuitry across human development, when these circuits are being fine-tuned and substantial changes in emotional control are observed. The present study examined developmental changes in amygdala-prefrontal circuitry across the ages of 4-22 years using task-based functional magnetic resonance imaging. Results suggest positive amygdala-prefrontal connectivity in early childhood that switches to negative functional connectivity during the transition to adolescence. Amygdala-medial prefrontal cortex functional connectivity was significantly positive (greater than zero) among participants younger than 10 years, whereas functional connectivity was significantly negative (less than zero) among participants 10 years and older, over and above the effect of amygdala reactivity. The developmental switch in functional connectivity was paralleled by a steady decline in amygdala reactivity. Moreover, the valence switch might explain age-related improvement in task performance and a developmentally normative decline in anxiety. Initial positive connectivity followed by a valence shift to negative connectivity provides a neurobiological basis for regulatory development and may present novel insight into a more general process of developing regulatory connections.

\section{Introduction}

Fundamental aspects of emotional behavior, including learning (Phelps et al., 2004; Milad et al., 2007; Delgado et al., 2008) and regulation (Ochsner et al., 2002; Lieberman et al., 2007; Goldin et al., 2008), rely on connections between the amygdala and medial prefrontal cortex (mPFC) (Banks et al., 2007). During normative human development, these emotional processes change dramatically (John and Gross, 2004), including gradual reductions in tantrums and separation anxiety, highlighting the importance of establishing a normative growth chart for amygdala-mPFC connectivity. The present study aims to examine how amygdalaprefrontal connections form a regulatory circuit across typical development.

Human neuroimaging studies in adults have revealed both structural (Kim and Whalen, 2009) and functional (Kim et al.,

\footnotetext{
Received July 18, 2012; revised Dec. 4, 2012; accepted Jan. 25, 2013.

Author contributions: D.G.G., K.L.H., J.F., B.G., E.H.T., M.S., T.A.H., S.Y.B., and N.T. designed research; D.G.G., K.L.H., J.F., B.G., E.H.T., M.S., and N.T. performed research; D.G.G., K.L.H., T.A.H., and N.T. analyzed data; D.G.G., T.A.H., S.Y.B., and N.T. wrote the paper.

This work was supported by National Institute of Mental Health Grant R01MH091864 (N.T.) and a National Science Foundation Graduate Research Fellowship award (D.G.G.). We thank B. J. Casey for helpful feedback on a previous version of this manuscript. We are grateful to Susan Bookheimer, Tyrone Cannon, John Piacentini, Elizabeth Sowell, and Regina Sullivan for serving as advisors on the National Institute of Mental Health BRAINS R01, which supports this project.

The authors declare no competing financial interests.

Correspondence should be addressed to Dr. Nim Tottenham, University of California, Los Angeles, 1285 Franz Hall, Box 951563, Los Angeles, CA 90095-1563. E-mail: nimtottenham@ucla.edu.

DOI:10.1523/JNEUROSCI.3446-12.2013

Copyright $\odot 2013$ the authors $\quad 0270-6474 / 13 / 334584-10 \$ 15.00 / 0$
}

2003; Pezawas et al., 2005; Hare et al., 2008; Roy et al., 2009) connections between amygdala and $\mathrm{mPFC}$, consistent with reciprocal connections identified in animal models (Amaral et al., 1992; Ghashghaei et al., 2007). Although functional magnetic resonance imaging (fMRI) methodology cannot determine the nature of inhibitory or excitatory influences, amygdala-mPFC functional coupling has been theorized to reflect top-down mPFC regulation of amygdala reactivity (Hariri et al., 2003; Kim et al., 2003; Pezawas et al., 2005; Hare et al., 2008).

The amygdala has shown evidence of early structural development (Giedd et al., 1996; Ulfig et al., 2003; Payne et al., 2010) and functionality (Baird et al., 1999; Thomas et al., 2001; Guyer et al., 2008; Hare et al., 2008). In contrast, animal studies indicate later mPFC development (Van Eden and Uylings, 1985). Human neuroimaging studies consistently demonstrate protracted development of lateral PFC, both structurally and functionally (Monk et al., 2003; Gogtay et al., 2004). However, research on the development of mPFC in humans has been scarce, which represents an important gap given the many studies in adults suggesting that $\mathrm{mPFC}$ plays a critical role in emotion regulation. The distinct time courses of amygdala and PFC may have important implications for how amygdala-mPFC connections arise.

Tracing studies suggest that amygdala-to-PFC projections emerge earlier than PFC-to-amygdala projections (Bouwmeester et al., 2002a,b), and these connections continue to develop through adolescence in rodents (Verwer et al., 1996; Cunningham et al., 2002; Kim and Richardson, 2009; Cressman et al., 2010). Although it is unclear how amygdala-mPFC connections 
develop among humans, research indicates important developmental changes during childhood and adolescence. For example, previous work suggests that effective connectivity in this circuitry increases with age (Perlman and Pelphrey, 2011). Moreover, connectivity between the amygdala and mPFC has been shown to be functional during the period of adolescence, because it predicts amygdala habituation within both adolescents and adults (Hare et al., 2008). However, to date, no study has examined amygdalamPFC connectivity across a continuous age span from young childhood through early adulthood. Despite clear developmental changes, the trajectory of amygdala-mPFC connectivity and its nature in early childhood remain unknown.

The present study aimed to chart human amygdala-mPFC development and its relationship to anticipated behavioral correlates based on the regulatory role of this circuitry. Motivated by animal studies demonstrating the emergence of adult-like amygdala-mPFC connections in adolescence, we anticipated an eventual developmental shift to adult-like negative connectivity. Amygdala-mPFC function has been associated with individual differences in anxiety but not yet to normative developmental changes in anxiety (e.g., separation from caregivers), which typically peaks early in childhood and declines throughout adolescence (Gullone and King, 1997; Beesdo et al., 2009). We predicted that amygdala-mPFC connectivity would mediate declines in both amygdala reactivity and separation anxiety across development. To test our hypotheses, the present study examined the typical development of amygdala reactivity and functional connectivity from early childhood through young adulthood.

\section{Materials and Methods Participants}

Participants were 45 healthy children, adolescents, and adults (19 females, 26 males), $4.0-22.3$ years old (mean \pm SD age, $13.2 \pm 5.2$ years). All participants were physically and psychiatrically healthy (no medical or psychiatric disorders), as confirmed by a telephone screening before participation. The Child Behavior Checklist (CBCL; Achenbach, 1991) was used to assess clinical symptoms, and all participants fell within the normal range on the CBCL Total Problems, Internalizing Problems, and Externalizing Problems scales. Participants were from European American (34.1\%), Asian American (22.7\%), African American (11.4\%), other (9.1\%), and Native Hawaiian or other Pacific Islander (2.3\%) backgrounds. Twenty percent $(20.5 \%)$ of participants identified as multiracial, including African American, Asian American, European American, and American Indian or Alaska Native backgrounds. Fifteen percent (15.9\%) of participants identified as Hispanic/Latino. Cognitive ability was assessed using the Wechsler Abbreviated Scale of Intelligence for participants 6-17 years old (assessments were conducted with 32 participants). The average full-scale intelligence quotient of the sample was within the average range (mean $\pm S D, 109.1 \pm 16.1$ ). Data on household income was obtained regarding the families of 34 child and adolescent participants, with a modal income range of $\$ 40,001-55,000$. Average intelligence and household income did not correlate with age $(p>0.05)$. All participants were right-handed. Anxiety was measured among child and adolescent participants using the Screen for Child Anxiety-Related Emotional Disorders (SCARED; parent report) (Birmaher et al., 1997). The protocol was approved by the Institutional Review Board at the University of California, Los Angeles. Participants provided informed consent or assent (parental informed consent for minors).

\section{Procedures}

\section{MRI task paradigm}

During the fMRI scan, participants completed two runs of an emotional faces task. The task consisted of a mixed design with one blocked variable (emotional valence: happy vs fearful) and one event-related variable (emotion vs neutral). During one run, participants viewed fearful faces interspersed with neutral faces, and during the other run, they viewed happy faces interspersed with neutral faces. Analyses focused on fearful faces for several reasons. Given robust amygdala activation to fearful faces in adults (Breiter et al., 1996; Whalen et al., 1998), these stimuli have been commonly studied and activate neural circuitry that is well delineated in adult samples. Moreover, previous research suggests that fearful faces engage the amygdala in children and adolescents (Baird et al., 1999; Thomas et al., 2001). Thus, in light of the paucity of research on amygdala function across development, it was advantageous to focus on fearful faces because of their highly common use in previous neuroimaging studies. The order of the fearful-neutral run and the happy-neutral run was counterbalanced across participants; the stimuli within each run were randomized and fixed across participants. To ensure that participants were paying attention, they were asked to press a button when they saw a neutral face. Female faces were selected from the Karolinska Directed Emotional Faces database (Lundqvist et al., 1998). The probability of a neutral face was $50 \%$ on any given trial. Stimuli were jittered (variable intertrial interval ranging from 3000 to $9000 \mathrm{~ms}$ ) and randomized based on a genetic algorithm (Wager and Nichols, 2003) to allow for unique estimates of the hemodynamic response for each trial type. Each run contained 48 trials ( 24 neutral faces, 24 fearful or happy faces). Each face was presented for $500 \mathrm{~ms}$.

\section{fMRI data acquisition}

Scanning was performed on a Siemens Trio 3.0 tesla MRI scanner. A standard radiofrequency head coil was used. For each participant, an initial two-dimensional spin echo image (TR, $4000 \mathrm{~ms}$; TE, $40 \mathrm{~ms}$; matrix size, $256 \times 256$; $4 \mathrm{~mm}$ thick; $0 \mathrm{~mm}$ gap) in the oblique plane was acquired to allow configuration of slices obtained in the structural and functional scans. A whole-brain high-resolution, $\mathrm{T}^{*}{ }^{*}$ weighted anatomical scan (MPRAGE; $256 \times 256$ in-plane resolution; $256 \mathrm{~mm}$ FOV; $192 \times 1 \mathrm{~mm}$ sagittal slices) was acquired for each participant for registration and localization of functional data to Talairach space (Talairach and Tournoux, 1988). The emotional faces task was presented on a computer screen through MR-compatible goggles. The task was completed during two functional scans. T2*weighted echoplanar images (interleaved) were collected at an oblique angle of $\sim 30^{\circ}$ (130 volumes/run; TR, 2000; TE, $30 \mathrm{~ms}$; flip angle, $90^{\circ}$; matrix size, $64 \times 64$; FOV, $192 \mathrm{~mm}$; 34 slices; $4 \mathrm{~mm}$ slice thickness; skip $0 \mathrm{~mm}$; 24 observations per event type).

\section{fMRI data analyses}

Functional imaging data were preprocessed and analyzed using the Analysis of Functional NeuroImages (AFNI) software package (Cox, 1996). All data were free of motion $>2.5 \mathrm{~mm}$ in any direction. Preprocessing of each individual's images included slice time correction to adjust for temporal differences in slice acquisition within each volume, spatial realignment to correct for head motion, registration to the first volume of each run, spatial smoothing using a $6 \mathrm{~mm}$ Gaussian kernel (FWHM) to increase the signal-to-noise ratio, and transformation into the standard coordinate space of Talairach and Tournoux (1988) with parameters obtained from the transformation of each individual's high-resolution anatomical scan. Talairached transformed images had a resampled resolution of $3 \mathrm{~mm}^{3}$. Time series were normalized to percentage signal change to allow for comparisons across runs and individuals. The functional runs were concatenated before creating two individual-level models for each participant to model activation and functional connectivity.

Motion correction. Systematic procedures were implemented to reduce motion, particularly in younger participants, and to ensure that children remained still throughout the duration of the task. Before the MRI scanning session, children participated in a mock scanning session to help them acclimate to the scanning environment and to feel comfortable with the scanning procedures. In addition, this step provided an opportunity for children to practice and receive feedback on lying still to optimize children's ability to remain still during actual data collection. During data collection, an air vacuum pillow (Siemens Comfort Pack) was used to pad and secure the child's head in a comfortable, steady position. Additional padding was placed around the child's head. In addition, all participants were provided with feedback and reminders regarding motion throughout the scanning session. 
Multiple steps were taken to correct for motion. All analyzed data were free of motion $>2.5 \mathrm{~mm}$ in any direction. Volumes with motion $>2.5$ $\mathrm{mm}$ in any direction were excluded (via censoring), and all participants had $<18 \%$ of total volumes censored (mean percentage of censored volumes, $1.3 \%$; mode, $0 \%$ ). Preprocessing included standard spatial realignment to correct for motion. Motion regressors were included in our imaging analyses (at the subject level, motion in all six directions at the trial-by-trial level). In addition, multiple analyses were conducted to rule out potential effects of motion. First, we tested motion related to our findings. Specifically, we tested whether average motion or motion in any of the six directions related to age, amygdala activation, or amygdalamPFC functional connectivity by using correlational analyses. Neither average motion nor motion in any of the six directions was correlated with any of these effects (all $p>0.05$ ). In addition, we tested for differences in average motion and motion in each of the six directions, between the four age groups. Using ANOVA, results showed no group differences in average motion or motion in any of the six directions (all $p>0.05$ ). Given recent advances in methods for controlling for motion, we also conducted a secondary analysis in which we reanalyzed our functional connectivity data controlling for different motion levels across participants (Van Dijk et al., 2012). The mean absolute displacement value was calculated for each participant and entered as a covariate into the wholebrain group-level regression of amygdala functional connectivity. Results of this secondary analysis replicated our original findings in amygdalamPFC functional connectivity. Moreover, mean displacement value was not associated with age, amygdala reactivity, or amygdala-mPFC functional connectivity (all $p>0.05$ ).

Brain activation to fear across development. To examine activation across the brain, each participant's individual-level model included regressors for each of the stimulus conditions [fearful faces, happy faces, neutral faces (in the fearful run), neutral faces (in the happy run)] and accuracy. The regressors were created by convolving the stimulus timing files with the canonical hemodynamic response function. Six motion parameters were included as separate regressors. General linear modeling (GLM) was performed to fit the percentage signal change time series to each regressor. Linear and quadratic trends were modeled for the time series of each voxel to control for correlated drift.

The individual-level regression coefficients were submitted to random-effects, group-level analyses. A regression analysis was conducted using the $3 \mathrm{dRegAna}$ program within AFNI to examine how neural responses to fearful faces (fear $>$ implicit baseline) changed as a function of age. Implicit baseline comprised unmodeled events (fixation) during the intertrial intervals. The contrast of fear versus baseline allowed for the contrasts of interest to be matched on motor and attentional demands. We examined all voxels across the brain to test how activation changed as a function of age, defined continuously. Correction for multiple comparisons was applied at the cluster level after Monte Carlo simulations conducted in the AlphaSim program within AFNI $(p<0.01)$. This method controls for type I errors, offering a reasonable correction for multiple tests during group-level analyses in regions of interest (ROIs).

Functional connectivity to fear across development. To examine functional connectivity as a function of age, a psychophysiological interaction (PPI) analysis was conducted to examine whether task-dependent functional connectivity with the amygdala changed across development. The amygdala mask was defined based on the age-related change in the amygdala because we aimed to examine how this particular amygdala cluster changed in connectivity with the mPFC across development. In addition, this region was selected to increase specificity, given known differences in amygdala functionality (Whalen et al., 2001) and connectivity within amygdala subregions (Roy et al., 2009). In this analysis, we took extra precaution to ensure that amygdala reactivity did not overly influence connectivity values in two ways. First, we controlled for amygdala reactivity at the trial level in the single-subject PPI analysis. Second, we included amygdala reactivity at the subject level as a regressor in our between-subjects analysis.

The PPI analysis tested whether the extent to which the amygdala covaried with other brain regions more during fearful faces than during baseline varied across age. A GLM analysis was performed in AFNI for each participant with regressors for task, seed region time series, interaction of task and time series, accuracy, and six motion regressors. Four psychological (task) regressors modeled whether a given trial consisted of viewing an emotional face [i.e., fearful, happy, neutral faces (in the fearful run), and neutral faces (in the happy run)] or fixation. Happy and neutral faces were modeled, but analyses focused on the contrast of fearful faces with baseline fixation. The physiological (seed region time series) regressor comprised the time series for the right amygdala cluster, as defined functionally based on the previous analysis of how activation changed across age. Four interaction regressors modeled the interaction of the psychological regressors and the physiological regressor, such that each interaction regressor identified regions whose time series correlated in a task-dependent manner with the amygdala time series. The GLM analyses fit the percentage signal change time series to each regressor, and linear and quadratic trends were modeled for the time series of each voxel to control for correlated drift.

The individual-level regression coefficients were then submitted to random-effects, group-level analyses. As with the amygdala activation analysis, we only examined connectivity specific to fear faces in the group analysis. A regression analysis was conducted using the $3 \mathrm{dRegAna}$ program in AFNI to examine how functional connectivity with the amygdala changed as a function of age across the whole brain. Correction for multiple comparisons was applied at the cluster level after Monte Carlo simulations conducted in the AlphaSim program within AFNI $(p<0.01)$. To further characterize the nature of age-related changes in amygdala$\mathrm{mPFC}$ functional connectivity and identify ages when significant changes occurred, we divided participants into four age groups $[4-9(n=12)$, $10-13(n=12), 14-17(n=12)$, and $18-22(n=9)$ years] and performed an ANOVA to test for differences in amygdala-mPFC functional connectivity between groups.

To further inform the results from the PPI analysis, we also examined the association between amygdala activation and mPFC activation to fearful faces across age. Specifically, we extracted $\beta$ weights of functional activation for the $\mathrm{mPFC}$, as identified by the region that was significantly functionally connected with the amygdala in the PPI analysis. A regression analysis was conducted to predict amygdala reactivity based on $\mathrm{mPFC}$ activation, age, and the interaction of $\mathrm{mPFC}$ activation $\times$ age. The interaction term was used to test whether age moderated an association between amygdala and $\mathrm{mPFC}$ activation. Given the contrast used in the PPI analysis, we also extracted $\beta$ weights for amygdala reactivity to baseline fixation to test whether reactivity to fixation changed across age. This analysis was performed with the aim of informing whether age-related changes in functional connectivity were likely driven by changes to fearful faces or changes to fixation. The analysis was partially redundant with the PPI analysis in its examination of amygdala-mPFC interactions. That is, the PPI analysis shows connectivity at the trial level for each subject, and the current analysis shows correlations between amygdala and mPFC at the subject level; both analyses show age-related change in connectivity valence. However, we present the subject-level correlations to provide another illustration of the changing nature of amygdala-mPFC connectivity across age.

\section{Behavioral data analyses}

For each participant, we calculated accuracy as the difference between the number of correct hits to neutral faces and the number of false alarms to fearful faces (i.e., pressing to a fearful face). Total errors equaled the sum of false alarms to fearful faces (errors of commission) and misses to neutral faces in the context of fearful faces (errors of omission). We calculated the mean reaction time for correct hits to neutral faces in the context of fearful faces. $D^{\prime}$, a measure of accuracy that accounts for response bias, was calculated by subtracting the $z$-transformed falsealarm rate from the $z$-transformed hit rate. Correlations tested relationships between age, task performance, and amygdala reactivity.

Developmentally normative anxiety was measured using the separation anxiety subscale of the SCARED parent-report questionnaire. We examined age-related changes in anxiety by performing a univariate ANOVA across the four age groups, and we tested for a relationship between anxiety and amygdala-mPFC functional connectivity. In addition, we used a mediational model to test whether the valence of amygda- 

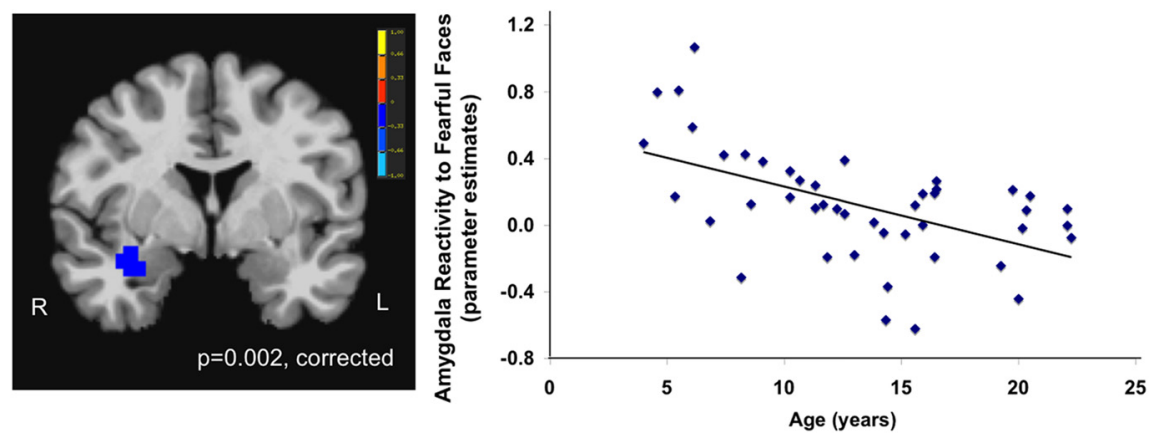

Figure 1. Age-related amygdala change. Amygdala reactivity to fearful faces decreased as a function of age, such that younger age was associated with the strongest amygdala signal change. The cluster of voxels in the right amygdala showed a negative correlation with age. L, Left; $R$, right.

la-mPFC functional connectivity might mediate a hypothesized agerelated decrease in anxiety.

\section{Results \\ Amygdala reactivity across development}

To examine changes in neural responses to fearful faces as a function of age, we conducted a regression analysis to examine regions in which activation depended on age across the whole brain. Results revealed only two regions that changed with age in response to fearful faces, which were the right amygdala and the left superior temporal sulcus (STS). Activation in the right amygdala (peak voxel: $32,-1,-16$ ) to fearful faces decreased across development $(t=-2.75$; cluster, 67 voxels; $p=0.002$, corrected) (Fig. $1)$, such that younger age was associated with the strongest amygdala signal change. In addition, activation in the left STS increased with age (peak voxel: $-61,-37,14 ; t=3.23$; cluster, 78 voxels; $p<0.0001$, corrected).

To characterize the anatomical location of the amygdala cluster that we identified as exhibiting an age-related decrease in reactivity, we overlaid this ROI with stereotaxic, probabilistic maps of cytoarchitectonic boundaries of the amygdala implemented as masks in the Juelich histological atlas (Eickhoff et al., 2005). The amygdala cluster identified in the present study overlapped to the greatest extent with the basolateral amygdala, with no overlap with the superficial or centromedial subdivision masks.

\section{Amygdala functional connectivity across development}

Given a change in amygdala reactivity to fearful faces with age, we aimed to characterize developmental changes in functional connectivity with the amygdala to fearful faces. Specifically, we examined voxels across the whole brain that covaried with the amygdala in a task-dependent manner (i.e., more for fearful faces than implicit baseline) using a PPI analysis that controlled for amygdala reactivity. The PPI analysis revealed that the only agerelated change in connectivity with the amygdala was with the mPFC; that is, amygdala functional connectivity with mPFC (peak voxel: $2,32,8$ ) became more strongly negative across development in response to fear $(t=-2.89$; cluster, 120 voxels; $p<$ 0.0001 , corrected) (Fig. 2) but not during baseline fixation $(p>$ $0.05)$. That is, amygdala-mPFC connectivity was greater for fearful faces than for baseline events in a manner that changed with age. Secondary analyses revealed that the findings were specific to fearful faces, because amygdala reactivity and amygdala-mPFC connectivity to happy faces did not change with age $(p>0.05)$.

Analyses were also performed with an anatomically defined amygdala seed (defined by a right amygdala mask in the Ta-
lairach-Tournoux atlas implemented in AFNI; Talairach and Tournoux, 1988) to further validate the PPI analysis. These secondary analyses replicated the findings that were obtained with the functionally defined amygdala region for both reactivity and amygdala-mPFC connectivity. Specifically, reactivity in the right amygdala decreased with age $(r=-0.352$; $p=0.018)$. The region of mPFC identified in the original analysis overlapped with the $\mathrm{mPFC}$ cluster identified in the functional connectivity analysis using the anatomical amygdala ROI (peak voxel: 2, 32, $8 ; t=-2.69$; cluster, 109 voxels; $p<$ 0.0001 , corrected). These analyses using the anatomically defined seed region of the amygdala added confirmation to our primary analyses using a functionally defined seed region.

To further characterize the nature of the age-related change in amygdala-mPFC connectivity and identify ages when significant changes occurred, we conducted a one-way ANOVA with participants split into the following age groups: $4-9(n=12), 10-13$ $(n=12), 14-17(n=12)$, and $18-22(n=9)$ years. Age groups for children and adolescents were selected based on equal sample sizes per group. There was a significant difference in the strength of amygdala-mPFC functional connectivity between the age groups (Fig. $3 ; F_{(3,41)}=7.243 ; p=0.001$ ). Post hoc comparisons using the Tukey's honestly significant difference test revealed that the mean \pm SD functional connectivity for 18-22 year olds $(-41.05 \pm 26.97)$ was most strongly negatively correlated between amygdala and $\mathrm{mPFC}$ and significantly differed from that of $4-9$ year olds $(9.49 \pm 27.20 ; p<0.0001), 10-13$ year olds $(-11.28 \pm 23.61 ; p=0.044)$, and $14-17$ year olds $(-8.62 \pm 21.05 ; p=0.024)$, and this effect remained when amygdala reactivity at the subject level was statistically controlled for $\left(F_{(3,40)}=6.01 ; p=0.002\right)$.

Moreover, we observed a switch from positive to negative functional connectivity between the amygdala and PFC around the age of 10 years. Amygdala-mPFC functional connectivity was significantly greater than zero among participants younger than 10 years $\left(t_{(11)}=2.71 ; p=0.020\right)$ and significantly less than zero among participants older than 10 years $\left(t_{(32)}=-2.51 ; p=\right.$ $0.017)$, controlling for amygdala reactivity. An independent samples $t$ test revealed a significant change in amygdala-mPFC functional connectivity for participants younger than 10 years versus those older than 10 years $\left(t_{(43)}=3.067 ; p=0.004\right)$, which remained significant over and above the effect of amygdala reactivity in a regression analysis $\left(F_{(1,42)}=6.52 ; p=0.014\right)$. Results were consistent with a shift from positive to negative functional connectivity, with a positive mean \pm SD functional connectivity for the younger group $(9.49 \pm 27.20)$ and a negative mean functional connectivity for the older group $(-18.43 \pm 26.92)$.

To further examine the changing nature of the relationship between the amygdala and mPFC across development, we examined functional activation of the amygdala and the mPFC at the subject level using extracted $\beta$ weights. Results of a moderation analysis revealed that age moderated the association between activation in the amygdala and activation in the mPFC $(B=$ $-0.303 ; t=-2.975 ; p=0.005$; Fig. 4). Specifically, for older individuals (adolescents and young adults), we observed a negative correlation between amygdala and $\mathrm{MPFC}$ activity, such that higher $\mathrm{mPFC}$ activation was associated with lower amygdala 
reactivity. However, among younger individuals (young children and children), these regions were positively correlated, in which higher MPFC activation was associated with higher amygdala reactivity. This statistical moderation further suggests that the nature of the relationship between amygdala and mPFC activation differs across development.

\section{fMRI task performance}

During the fMRI task, participants were presented with randomly ordered neutral and fear faces and were instructed to quickly press a button for each neutral face but not for the fear faces. On average, participants correctly pressed to neutral faces for $78 \pm 25 \%$ (mean $\pm \mathrm{SD}$ ) of the trials and incorrectly pressed to fear faces for $13 \pm 19 \%$ of the trials. Across all participants, the mean \pm reaction time for correct trials was $702.3 \pm 173.2 \mathrm{~ms}$. The average \pm SD $D^{\prime}$ across the overall sample was $2.67 \pm 1.24$. Total errors (errors of commission plus errors of omission) decreased with age $(r=-0.569 ; p<$ $0.0001)$, and reaction time became faster with age $(r=-0.353 ; p=0.020)$ (Table 1 ; Fig. 5). $D^{\prime}$ also increased with age $(r=$ $0.593 ; p<0.0001)$.

\section{Normative anxiety and amygdala-mPFC connectivity}

We collected parent report of normative anxiety-related behaviors for the children and adolescents, with the anticipation that behaviors such as separation anxiety would decline with age. Results confirmed that normative separation anxiety among children and adolescents declined with age $\left(F_{(2,31)}=5.31 ; p=0.011\right)$ and revealed an association between the switch from positive to negative connectivity and developmentally normative separation anxiety. There was a significant mediation effect of amygdala-mPFC functional connectivity valence (positive or negative) on the expected age-related decrease in separation anxiety, such that the connectivity valence mediated the association between age and anxiety (Fig. 6). Hierarchical regression analyses were used to test the mediation model. Results demonstrated that the statistical association between age and anxiety became weaker when the valence of amygdala-mPFC functional connectivity was included in the model $(B=$ $-0.480 ; t=-3.254 ; p=0.003$; adjusted $R^{2}=0.393$; Sobel test, $\left.Z=-2.18, p<0.05\right)$. Moreover, the valence of amygdala-mPFC functional connectivity was associated with separation anxiety, such that when controlling for age, those participants with negative connectivity tended to have lower anxiety, whereas those participants with positive connec-
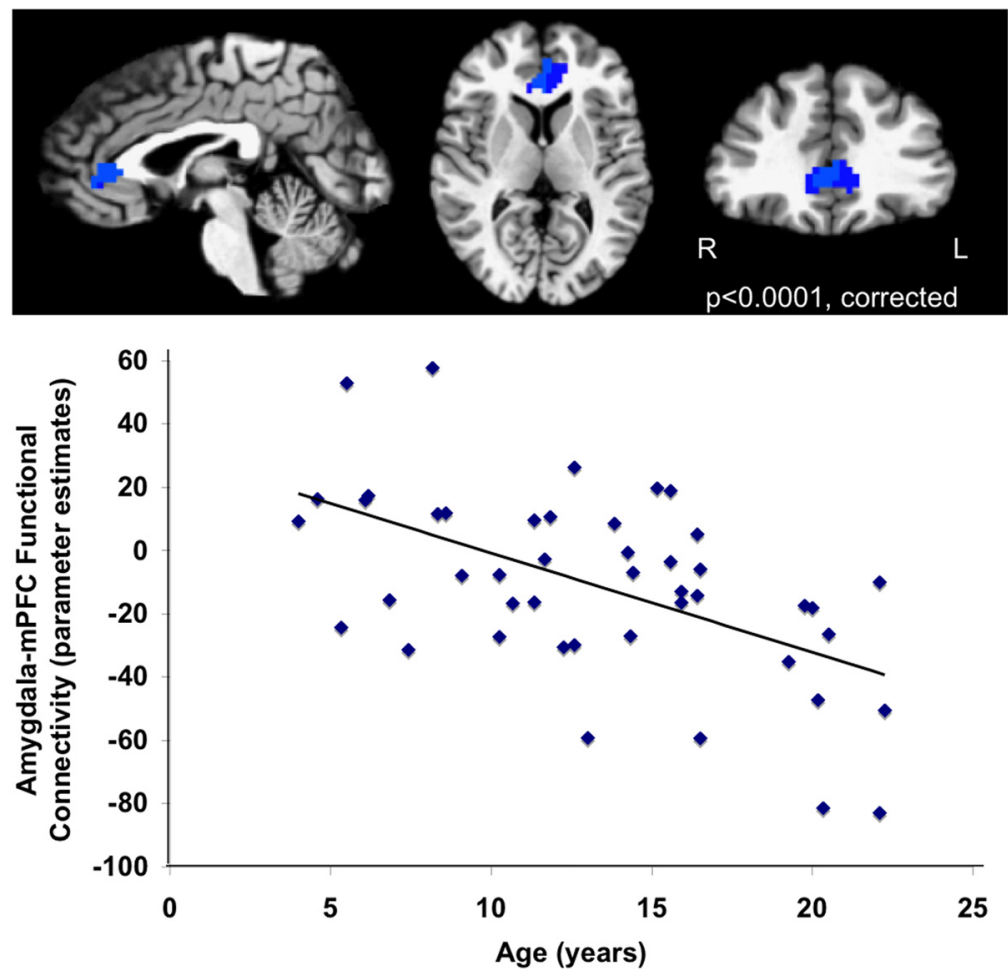

Figure 2. Age-related amygdala-mPFC connectivity change. Functional connectivity between the amygdala and mPFC became more strongly negative with age (peak voxel: $2,32,8$ ). Age-related change in functional connectivity with the amygdala during the viewing of fearful faces was specific to mPFC. L, Left; $R$, right.

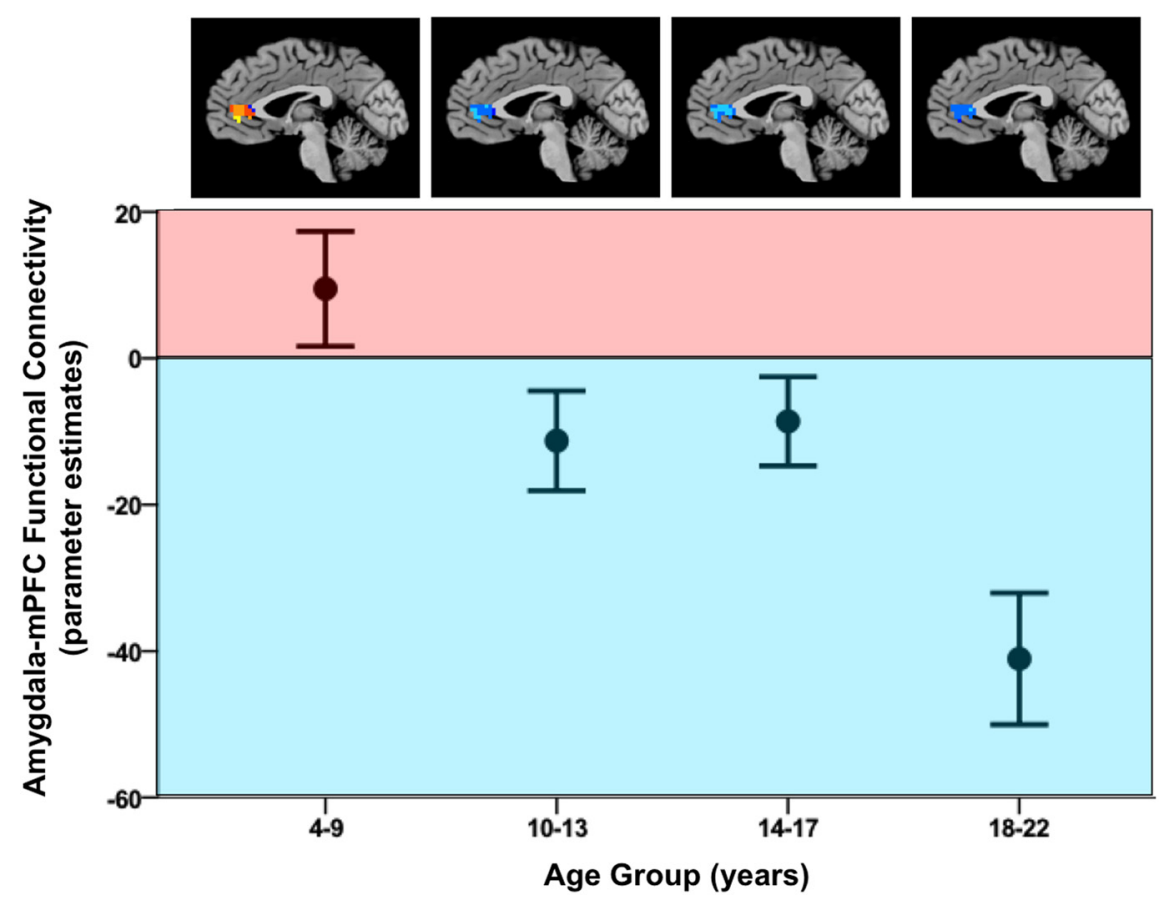

Figure 3. Developmental switch in amygdala-mPFC connectivity. A developmental switch from positive to negative functional connectivity between the amygdala and mPFC was observed during the transition from childhood to adolescence. Younger children displayed positive functional connectivity, which became increasingly negative with age.

tivity tended to have higher anxiety, as reported by their parents $\left(F_{(2,31)}=4.83 ; p=0.036\right)$. Of note, the valence, but not the magnitude, of connectivity was associated with anxiety. That is, magnitude of connectivity did not relate to anxiety in participants with positive connectivity $(p>0.05)$ or in participants 


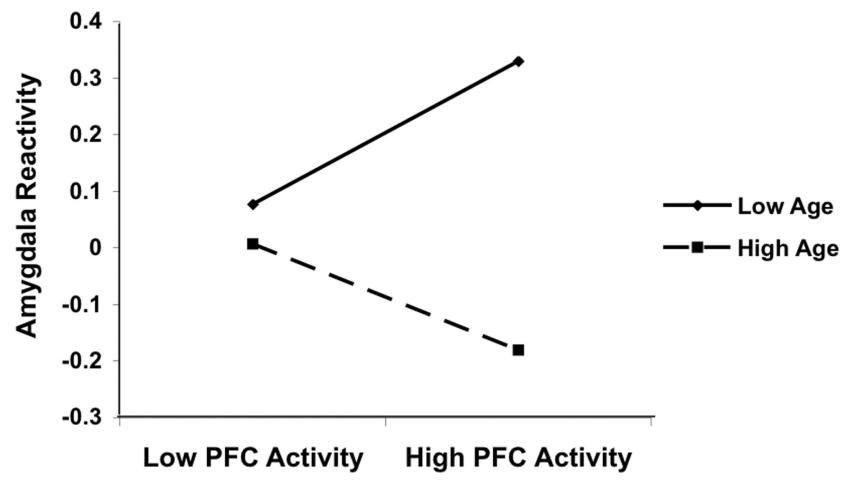

Figure 4. Moderation of amygdala-mPFC relationship. Age moderated the association between amygdala and mPFC activation, suggesting that the nature of the relationship between these regions might differ across developmental stages. Specifically, older individuals (adolescents and young adults) exhibited a negative correlation between amygdala and mPFC activity, such that higher mPFC activation was associated with lower amygdala reactivity. Younger individuals (young children and children) displayed a positive correlation between amygdala and mPFC activity, in which higher mPFC activation was associated with higher amygdala reactivity.

Table 1. Behavioral performance by age group

\begin{tabular}{lcccc}
\hline & Age group 1 & Age group 2 & Age group 3 & Age group 4 \\
\hline Total errors & $12.4 \pm 6.0$ & $10.6 \pm 7.5$ & $4.7 \pm 5.4$ & $3.8 \pm 3.8$ \\
RT (correct hits) & $806.8 \pm 207.3$ & $637.7 \pm 125.3$ & $703.1 \pm 142.9$ & $633.6 \pm 160.7$ \\
$D^{\prime}$ & $1.7 \pm 1.1$ & $2.2 \pm 1.1$ & $3.4 \pm 1.0$ & $3.5 \pm 0.7$ \\
\hline
\end{tabular}

Behavioral performance was measured by total errors (errors of omission plus errors of commission), reaction time (RT) for correct hits to neutral faces in the context of fearful faces, and $D^{\prime}$.

with negative connectivity $(p>0.05)$, and the weight of the valence (i.e., absolute value) did not relate to anxiety in the overall sample $(p>0.05)$. These associations were also not significant when partial correlations were conducted to control for age $(p>$ $0.05)$. Amygdala reactivity was not associated with anxiety, over and above the effect of age $(p>0.05)$. Together, this model suggests that a developmentally normative decline in separation anxiety is partially mediated by the switch from positive to negative amygdala-mPFC connectivity.

\section{Discussion}

To elucidate changes in amygdala-mPFC interactions across typical development, the present study examined the trajectories of amygdala reactivity and amygdala-mPFC functional connectivity to fearful faces from early childhood through early adulthood in a cross-sectional sample. Findings revealed a valence shift in functional connectivity between the amygdala and $\mathrm{mPFC}$, which began in early childhood as a positive coupling and became more strongly negative across development. Specifically, we observed a switch from positive to negative functional connectivity around the transition from childhood to adolescence. Consistent with a theorized regulatory role of $\mathrm{mPFC}$, amygdala reactivity decreased across development, as did normative separation anxiety. Moreover, the valence switch related to individual differences in anxiety and behavior during task-based performance, over and above the effect of age. The developmental switch represents a potential neurobiological basis for the improvements in emotion regulation that have been observed across development. Moreover, the change from positive to negative connectivity in a wellestablished regulatory circuit may provide novel insight and an intriguing model for the more general development of regulatory connections in the brain.
The observed changes in amygdala-mPFC coupling consisted of a switch from positive connectivity in younger children to negative connectivity among early adolescents and ultimately a strongly negative correlation in adulthood, replicating previous studies of adult amygdala-mPFC connectivity (Kim et al., 2003, 2011; Hare et al., 2008). The mPFC was the only region that showed significant age-related change in connectivity with the amygdala, underscoring the substantial shift that occurs in this circuitry across childhood and adolescence. Results of the PPI analysis held when statistically controlling for amygdala reactivity at the level of the trial and individual participant; thus, the connectivity findings cannot be explained by higher amygdala reactivity among the youngest children. Moreover, amygdala reactivity exhibited age-related changes to fearful faces but not to fixation, indicating that the findings were not an artifact of the task contrast.

Although brain function in children and adolescents has sometimes been characterized as immature relative to adults, it is valuable to consider the potential function of early positive connectivity in younger children. The temporally discrepant developmental courses of the amygdala and PFC may contribute to changes in connectivity across development. For example, earlier amygdala development may drive heavier bottom-up signaling early in life. For amygdala-mPFC connections to emerge, it may be that intrinsic amygdala activity initially signals to mPFC and that top-down signaling increasingly emerges over time. Consistent with these exploratory possibilities are findings of robust bottom-up anatomical connections demonstrated in animal studies (Ghashghaei et al., 2007) and the observation of amygdala-originating inputs to the mPFC earlier than mPFCoriginating inputs to the amygdala among rodents (Cressman et al., 2010). Moreover, early positive connectivity may facilitate connectivity, whereas initial inhibitory input would seem to discourage the development of connections between regions. Consistent with these ideas, age moderated the association between amygdala reactivity and $\mathrm{mPFC}$ activation to fearful faces in the present study, suggesting that the nature of amygdala-mPFC interactions may vary across development. The association between higher mPFC activation and higher amygdala reactivity among younger participants may be consistent with bottom-up signaling, whereas the association between higher mPFC activation and lower amygdala reactivity among older participants may reflect enhanced top-down modulation later in life.

It is important to note that distinguishing between inhibitory and excitatory influences may extend beyond the realm of fMRI methods. Although some evidence from fMRI studies suggests that negative connectivity between the amygdala and $\mathrm{mPFC}$ reflects inhibitory influences of the mPFC on the amygdala (Hariri et al., 2003; Kim et al., 2003; Hare et al., 2008), positive connectivity has also been theorized to reflect top-down $\mathrm{mPFC}$ regulation of amygdala reactivity (e.g., via connections with inhibitory interneurons within the amygdala) (Milad et al., 2007; Delgado et al., 2008; Linnman et al., 2011). Thus, future work, particularly using translational approaches, is needed to further elucidate the nature of amygdala-mPFC connections.

Although the present methodology does not allow for inferences about the direction of influence between the amygdala and $\mathrm{mPFC}$, examination at the cellular level has identified developmental switching in the valence of connectivity across several modalities (Ganguly et al., 2001; Ben-Ari, 2002; Gillespie et al., 2005; Lodato et al., 2011). Thus, should such principles hold, our findings may be a recapitulation at the systems level of developmental processes for inhibitory connectivity that have been iden- 
tified at the cellular level. More generally throughout the brain, increased positive connectivity early in life may be necessary to establish a connection that eventually evolves into a regulatory circuit. Longitudinal studies may elucidate whether initial intrinsic amygdala activity ultimately gives rise to connections with mPFC earlier in life and to more generally provide initial insight into the development of regulatory connections at the systems level.

The developmental valence shift observed in amygdala-mPFC circuitry may hold important functional implications for normative changes and individual differences in emotion regulation. For example, the observed shift from positive to negative valence mediated the relationship between age and developmentally normative decreases in separation anxiety. Previous research has demonstrated improved behavioral regulation with age across a range of tasks (Mischel and Underwood, 1974; Diamond, 1985; Zelazo et al., 1996; Casey et al., 1997; Bunge et al., 2002), consistent with our findings showing age-related changes in emotional behavior. Given the role of mPFC in regulating amygdala reactivity, evidence of stronger negative connectivity and decreased amygdala reactivity with age may provide a neurobiological basis for age-related improvements in emotion regulation. Consistently, the present findings demonstrated a corresponding decrease in separation anxiety and improved performance. Our finding that stronger amygdala-mPFC connectivity predicts lower anxiety parallels previous findings that stronger amygdalaPFC connectivity related to greater amygdala habituation, which correlated with decreased anxiety (Hare et al., 2008). The present work extends knowledge of this circuitry into early childhood and specifically implicates a valence switch in typical developmental changes in separation anxiety. As such, we expand on previous findings of individual differences related to the strength of amygdala-mPFC connectivity among adults to demonstrate behavioral differences throughout development that may be driven by this circuitry. Our findings suggest substantial functional significance of developmental shifts in amygdala reactivity and connectivity and are consistent with the wealth of adult neuroimaging studies demonstrating the relevance of amygdala-mPFC connectivity to emotion regulation and anxiety. Although the valence but not the magnitude of connectivity was associated with anxiety in the present study, future research may elucidate potential developmental influences of the magnitude or strength of amygdala-mPFC connectivity on age-related changes in anxiety.

Amygdala reactivity to fearful faces also decreased with age, indicating continued functional change from young childhood through early adulthood. Although decreased amygdala reactivity is consistent with enhanced regulation and stronger connectivity with $\mathrm{mPFC}$, changes in amygdala reactivity were independent of changes in connectivity in the present study, suggesting that functional activation and connectivity both exhibit distinct developmental changes. The current findings suggest that, within the age range tested, amygdala reactivity to fearful
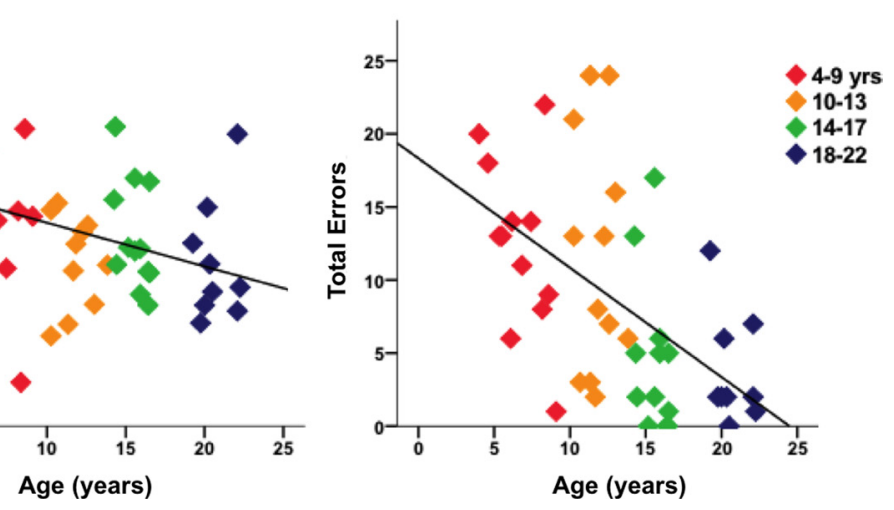

ge (years)

roved across development, such that total errors (false alarms plus

Figure 5. Behavioral performance and age. Performance improve
errors of omission) decreased and reaction time became faster.

Figure 6. Amygdala-mPFC connectivity valence and anxiety. The valence of connectivity was associated with developmentally normative anxiety over and above the effect of age, such that individuals with negative connectivity tended to have lower anxiety. The switch from positive to negative connectivity mediated an age-related decline in separation anxiety.

faces peaks during early childhood. Previous research has observed amygdala activation in an inverted U-shaped curve with age, with a peak in adolescence (Hare et al., 2008). The distinct trajectory observed at present likely follows from differences in both task design and conditions. The present study examined fearful faces in the context of neutral faces, whereas previous work (Hare et al., 2008) collapsed across all emotional conditions, including calm and happy, in an emotional go/no-go task. Thus, it is important to interpret the present finding of decreased reactivity in the context of fearful faces, which are a salient but relatively infrequent stimulus in natural environments (Somerville and Whalen, 2006). It remains unclear whether the observed age-related decrease in amygdala reactivity is stimulus specific or represents a general reduction in reactivity across development. In addition to changes in amygdala reactivity, we observed that STS activation to fearful faces increased with age. Of note, these were the only two regions in which we observed changes with age to fearful faces, and both the amygdala and STS are face-sensitive regions. Although speculative, the age-related changes in STS and amygdala responses may reflect developmental shifts in the dynamics of the distributed face processing system (Haxby et al., 2000). These results provide novel insight into the emergence of amygdala-mPFC connections and more fully characterize changes in amygdala reactivity across development.

The lateralization of our age-related findings in the right amygdala and left STS may stem from functional differences between the cerebral hemispheres in these regions. Meta-analyses of amygdala activation to emotional stimuli have demonstrated more left- than right-lateralized activations (Wager et al., 2003; Baas et al., 2004; Sergerie et al., 2008). However, evidence suggests that the right amygdala may be particularly involved in fear conditioning (Baker and Kim, 2004) and processing non- 
semantic stimuli, such as faces (Markowitsch, 1998; Phelps et al., 2001; Sergerie et al., 2008). In addition, laterality effects related to temporal dynamics have been proposed (Gläscher and Adolphs, 2003) based on differential habituation rates in the left and right amygdala (Whalen et al., 1998; Phillips et al., 2001; Wright et al., 2001). Following evidence for right amygdala involvement in the rapid detection of emotional stimuli and the left amygdala in more elaborate evaluation of stimuli, a meta-analysis demonstrated differences in lateralization for block and event-related designs (Sergerie et al., 2008). Specifically, left amygdala activations were more common in block designs, whereas left and right activations were comparable in event-related designs, possibly attributable to the random presentation in event-related designs preventing rapid habituation in the right amygdala (Sergerie et al., 2008). Consistent with these observations, a more robust effect in the right amygdala may have stemmed from our eventrelated design involving the detection of emotional facial expressions. Although activation in the STS is typically rightlateralized for face processing (Narumoto et al., 2001; Pelphrey et al., 2004), left STS activation has been observed for more subtle gradations in face processing (Said et al., 2010). Thus, it may be that the observed increase in left STS activation relates to increasing complexity in the processing of faces across development.

The present study had several limitations that may be further addressed in future research. Given the broad age range of participants, the registration of imaging data in pediatric samples is relevant to the present study. Despite an ongoing question of whether a separate template should be used for registration in young children, some evidence indicates that comparison of structural and functional MRI data between young children and adults is methodologically appropriate (Burgund et al., 2002; Kang et al., 2003). Although future research will help to elucidate this issue, the lack of age-related change in amygdala reactivity and connectivity to implicit baseline events suggests that the observed developmental changes to fearful faces were not attributable to registering the children's data to a standard template. In addition, the present study compared fearful faces with implicit baseline, because fearful and neutral events differed on dimensions such as motor response and attention in the present work. Future research may benefit from task conditions that are matched on such dimensions to better isolate relevant variables, such as emotional expression. Given that the task stimuli were limited to Caucasian female faces, results on amygdala activation during the present study may not generalize to other faces. The present investigation also relied on a cross-sectional design, which can be influenced by interindividual variance and factors that limit its ability to characterize developmental trajectories. Thus, future longitudinal examinations of amygdala reactivity and connectivity will be necessary. In addition, PPI analyses rely on statistical correlations and thus cannot address questions of directionality in regional influences. Methods such as increased use of translational approaches, including animal models (McDonald, 1991; Moriceau et al., 2006; Akirav and Maroun, 2007; Ghashghaei et al., 2007), would enhance knowledge of the directional influences between amygdala and mPFC.

The present study demonstrates a valence switch in amygdalamPFC functional connectivity during the transition to adolescence, which appears to hold great import for emotion regulation, including individual differences in regulation and normative developmental decreases in separation anxiety. Beyond the import of this research for understanding the development of emotion regulation and amygdala-mPFC circuitry, the present study has the potential to inform neuroscientific research on a broader scope. Given the neurodevelopmental nature of many psychiatric disorders and the increase in risk for psychopathology in adolescence (Pine et al., 1998; Angold et al., 1999), present findings on typical development may serve as an important reference for understanding aberrations in the maturation of amygdala-mPFC connections across disorders in which this circuitry has been implicated (Davis and Whalen, 2001). Moreover, the observation of a switch from positive to negative connectivity throughout the development of a regulatory circuit may provide novel insight into the neural mechanisms underlying the development of regulatory connections in the brain.

\section{References}

Achenbach TM (1991) Manual for the Child Behavior Checklist/4-18 and 1991 Profile. Burlington, VT: Department of Psychiatry, University of Vermont.

Akirav I, Maroun M (2007) The role of the medial prefrontal cortexamygdala circuit in stress effects on the extinction of fear. Neural Plast 2007:30873. CrossRef Medline

Amaral DG, Price JL, Pitkanen A, Carmichael ST (1992) Anatomical organization of the primate amygdaloid complex. In: The amygala: neurobiological aspects of emotion, memory, and mental dysfunction. New York: Wiley.

Angold A, Costello EJ, Erkanli A, Worthman CM (1999) Pubertal changes in hormone levels and depression in girls. Psychol Med 29:1043-1053. CrossRef Medline

Baas D, Aleman A, Kahn RS (2004) Lateralization of amygdala activation: a systematic review of functional neuroimaging studies. Brain Res Brain Res Rev 45:96-103. CrossRef Medline

Baird AA, Gruber SA, Fein DA, Maas LC, Steingard RJ, Renshaw PF, Cohen BM, Yurgelun-Todd DA (1999) Functional magnetic resonance imaging of facial affect recognition in children and adolescents. J Am Acad Child Adolesc Psychiatry 38:195-199. CrossRef Medline

Baker KB, Kim JJ (2004) Amygdalar lateralization in fear conditioning: evidence for greater involvement of the right amygdala. Behav Neurosci 118:15-23. CrossRef Medline

Banks SJ, Eddy KT, Angstadt M, Nathan PJ, Phan KL (2007) Amygdalafrontal connectivity during emotion regulation. Soc Cogn Affect Neurosci 2:303-312. CrossRef Medline

Beesdo K, Knappe S, Pine DS (2009) Anxiety and anxiety disorders in children and adolescents: developmental issues and implications for DSM-V. Psychiatr Clin North Am 32:483-524. CrossRef Medline

Ben-AriY (2002) Excitatory actions of gaba during development: the nature of the nurture. Nat Rev Neurosci 3:728-739. CrossRef Medline

Birmaher B, Khetarpal S, Brent D, Cully M, Balach L, Kaufman J, Neer SM (1997) The Screen for Child Anxiety Related Emotional Disorders (SCARED): scale construction and psychometric characteristics. J Am Acad Child Adolesc Psychiatry 36:545-553. CrossRef Medline

Bouwmeester H, Smits K, Van Ree JM (2002a) Neonatal development of projections to the basolateral amygdala from prefrontal and thalamic structures in rat. J Comp Neurol 450:241-255. CrossRef Medline

Bouwmeester H, Wolterink G, van Ree JM (2002b) Neonatal development of projections from the basolateral amygdala to prefrontal, striatal, and thalamic structures in the rat. J Comp Neurol 442:239-249. CrossRef Medline

Breiter HC, Etcoff NL, Whalen PJ, Kennedy WA, Rauch SL, Buckner RL, Strauss MM, Hyman SE, Rosen BR (1996) Response and habituation of the human amygdala during visual processing of facial expression. Neuron 17:875-887. CrossRef Medline

Bunge SA, Dudukovic NM, Thomason ME, Vaidya CJ, Gabrieli JD (2002) Immature frontal lobe contributions to cognitive control in children: evidence from fMRI. Neuron 33:301-311. CrossRef Medline

Burgund ED, Kang HC, Kelly JE, Buckner RL, Snyder AZ, Petersen SE, Schlaggar BL (2002) The feasibility of a common stereotactic space for children and adults in fMRI studies of development. Neuroimage 17:184200. CrossRef Medline

Casey BJ, Trainor RJ, Orendi JL, Schubert AB, Nystrom LE, Giedd JN, Castellanos FX, Haxby JV, Noll DC, Cohen JD, Forman SD, Dahl RE, Rapoport JL (1997) A developmental functional MRI study of prefrontal activation during performance of a go-no-go task. J Cogn Neurosci 9:835-847. CrossRef 
Cox RW (1996) AFNI: software for analysis and visualization of functional magnetic resonance neuroimages. Comput Biomed Res 29:162-173. CrossRef Medline

Cressman VL, Balaban J, Steinfeld S, Shemyakin A, Graham P, Parisot N, Moore H (2010) Prefrontal cortical inputs to the basal amygdala undergo pruning during late adolescence in the rat. J Comp Neurol 518: 2693-2709. CrossRef Medline

Cunningham MG, Bhattacharyya S, Benes FM (2002) Amygdalo-cortical sprouting continues into early adulthood: implications for the development of normal and abnormal function during adolescence. J Comp Neurol 453:116-130. CrossRef Medline

Davis M, Whalen PJ (2001) The amygdala: vigilance and emotion. Mol Psychiatry 6:13-34. CrossRef Medline

Delgado MR, Nearing KI, Ledoux JE, Phelps EA (2008) Neural circuitry underlying the regulation of conditioned fear and its relation to extinction. Neuron 59:829-838. CrossRef Medline

Diamond A (1985) Development of the ability to use recall to guide action, as indicated by infants' performance on AB. Child Dev 56:868-883. CrossRef Medline

Eickhoff S, Stephan KE, Mohlberg H, Grefkes C, Fink GR, Amunts K, Zilles K (2005) A new SPM toolbox for combining probabilistic maps and functional imaging data. Neuroimage 25:1325-1335. CrossRef Medline

Ganguly K, Schinder AF, Wong ST, Poo M (2001) GABA itself promotes the developmental switch of neuronal GABAergic responses from excitation to inhibition. Cell 105:521-532. CrossRef Medline

Ghashghaei HT, Hilgetag CC, Barbas H (2007) Sequence of information processing for emotions based on the anatomic dialogue between prefrontal cortex and amygdala. Neuroimage 34:905-923. CrossRef Medline

Giedd JN, Vaituzis AC, Hamburger SD, Lange N, Rajapakse JC, Kaysen D, Vauss YC, Rapoport JL (1996) Quantitative MRI of the temporal lobe, amygdala, and hippocampus in normal human development: ages 4-18 years. J Comp Neurol 366:223-230. CrossRef Medline

Gillespie DC, Kim G, Kandler K (2005) Inhibitory synapses in the developing auditory system are glutamatergic. Nat Neurosci 8:332-338. CrossRef Medline

Gläscher J, Adolphs R (2003) Processing of the arousal of subliminal and supraliminal emotional stimuli by the human amygdala. J Neurosci 23: 10274-10282. Medline

Gogtay N, Giedd JN, Lusk L, Hayashi KM, Greenstein D, Vaituzis AC, Nugent TF 3rd, Herman DH, Clasen LS, Toga AW, Rapoport JL, Thompson PM (2004) Dynamic mapping of human cortical development during childhood through early adulthood. Proc Natl Acad Sci U S A 101:8174-8179. CrossRef Medline

Goldin PR, McRae K, Ramel W, Gross JJ (2008) The neural bases of emotion regulation: reappraisal and suppression of negative emotion. Biol Psychiatry 63:577-586. CrossRef Medline

Gullone E, King NJ (1997) Three year follow up of normal fear in children and adolescents aged 7 to 18 years. Br J Dev Psychol 15:97-111. CrossRef

Guyer AE, Monk CS, McClure-Tone EB, Nelson EE, Roberson-Nay R, Adler AD, Fromm SJ, Leibenluft E, Pine DS, Ernst M (2008) A developmental examination of amygdala response to facial expressions. J Cogn Neurosci 20:1565-1582. CrossRef Medline

Hare TA, Tottenham N, Galvan A, Voss HU, Glover GH, Casey BJ (2008) Biological substrates of emotional reactivity and regulation in adolescence during an emotional go-nogo task. Biol Psychiatry 63:927-934. CrossRef Medline

Hariri AR, Mattay VS, Tessitore A, Fera F, Weinberger DR (2003) Neocortical modulation of the amygdala response to fearful stimuli. Biol Psychiatry 53:494-501. CrossRef Medline

Haxby JV, Hoffman EA, Gobbini MI (2000) The distributed human neural system for face perception. Trends Cogn Sci 4:223-233. CrossRef Medline

John OP, Gross JJ (2004) Healthy and unhealthy emotion regulation: personality processes, individual differences, and life span development. J Pers 72:1301-1333. CrossRef Medline

Kang HC, Burgund ED, Lugar HM, Petersen SE, Schlaggar BL (2003) Comparison of functional activation foci in children and adults using a common stereotactic space. Neuroimage 19:16-28. CrossRef Medline

Kim H, Somerville LH, Johnstone T, Alexander AL, Whalen PJ (2003) Inverse amygdala and medial prefrontal cortex responses to surprised faces. Neuroreport 14:2317-2322. CrossRef Medline

Kim JH, Richardson R (2009) The effect of the mu-opioid receptor antago- nist naloxone on extinction of conditioned fear in the developing rat. Learn Mem 16:161-166. CrossRef Medline

Kim MJ, Whalen PJ (2009) The structural integrity of an amygdala-prefrontal pathway predicts trait anxiety. J Neurosci 29:11614-11618. CrossRef Medline

Kim MJ, Loucks RA, Palmer AL, Brown AC, Solomon KM, Marchante AN, Whalen PJ (2011) The structural and functional connectivity of the amygdala: From normal emotion to pathological anxiety. Behav Brain Res 223:403-410. CrossRef Medline

Lieberman MD, Eisenberger NI, Crockett MJ, Tom SM, Pfeifer JH, Way BM (2007) Putting feelings into words: affect labeling disrupts amygdala activity in response to affective stimuli. Psychol Sci 18:421-428. CrossRef Medline

Linnman C, Zeffiro TA, Pitman RK, Milad MR (2011) An fMRI study of unconditioned responses in post-traumatic stress disorder. Biol Mood Anxiety Disord 1:8. CrossRef Medline

Lodato S, Rouaux C, Quast KB, Jantrachotechatchawan C, Studer M, Hensch TK, Arlotta P (2011) Excitatory projection neuron subtypes control the distribution of local inhibitory interneurons in the cerebral cortex. Neuron 69:763-779. CrossRef Medline

Lundqvist D, Flykt A, Ohman A (1998) Karolinska directed emotional faces. Stockholm: Psychology Section, Department of Clinical Neuroscience, Karolinska Institute.

Markowitsch HJ (1998) Differential contribution of right and left amygdala to affective information processing. Behav Neurol 11:233-244. Medline

McDonald AJ (1991) Organization of amygdaloid projections to the prefrontal cortex and associated striatum in the rat. Neuroscience 44:1-14. CrossRef Medline

Milad MR, Wright CI, Orr SP, Pitman RK, Quirk GJ, Rauch SL (2007) Recall of fear extinction in humans activates the ventromedial prefrontal cortex and hippocampus in concert. Biol Psychiatry 62:446-454. CrossRef Medline

Mischel W, Underwood B (1974) Instrumental ideation in delay of gratification. Child Dev 45:1083-1088. CrossRef Medline

Monk CS, McClure EB, Nelson EE, Zarahn E, Bilder RM, Leibenluft E, Charney DS, Ernst M, Pine DS (2003) Adolescent immaturity in attentionrelated brain engagement to emotional facial expressions. Neuroimage 20:420-428. CrossRef Medline

Moriceau S, Wilson DA, Levine S, Sullivan RM (2006) Dual circuitry for odor-shock conditioning during infancy: corticosterone switches between fear and attraction via amygdala. J Neurosci 26:6737-6748. CrossRef Medline

Narumoto J, Okada T, Sadato N, Fukui K, Yonekura Y (2001) Attention to emotion modulates fMRI activity in human right superior temporal sulcus. Brain Res Cogn Brain Res 12:225-231. CrossRef Medline

Ochsner KN, Bunge SA, Gross JJ, Gabrieli JD (2002) Rethinking feelings: an fMRI study of the cognitive regulation of emotion. J Cogn Neurosci 14: 1215-1229. CrossRef Medline

Payne C, Machado CJ, Bliwise NG, Bachevalier J (2010) Maturation of the hippocampal formation and amygdala in Macaca mulatta: a volumetric magnetic resonance imaging study. Hippocampus 20:922-935. CrossRef Medline

Pelphrey KA, Viola RJ, McCarthy G (2004) When strangers pass processing of mutual and averted social gaze in the superior temporal sulcus. Psychol Sci 15:598-603. CrossRef Medline

Perlman SB, Pelphrey KA (2011) Developing connections for affective regulation: age-related changes in emotional brain connectivity. J Exp Child Psychol 108:607-620. CrossRef Medline

Pezawas L, Meyer-Lindenberg A, Drabant EM, Verchinski BA, Munoz KE, Kolachana BS, Egan MF, Mattay VS, Hariri AR, Weinberger DR (2005) 5-HTTLPR polymorphism impacts human cingulate-amygdala interactions: a genetic susceptibility mechanism for depression. Nat Neurosci 8:828-834. CrossRef Medline

Phelps EA, O'Connor KJ, Gatenby JC, Gore JC, Grillon C, Davis M (2001) Activation of the left amygdala to a cognitive representation of fear. Nat Neurosci 4:437-441. CrossRef Medline

Phelps EA, Delgado MR, Nearing KI, LeDoux JE (2004) Extinction learning in humans: role of the amygdala and vmPFC. Neuron 43:897-905. CrossRef Medline

Phillips ML, Medford N, Young AW, Williams L, Williams SC, Bullmore ET, Gray JA, Brammer MJ (2001) Time courses of left and right amygdalar 
responses to fearful facial expressions. Hum Brain Mapp 12:193-202. CrossRef Medline

Pine DS, Cohen P, Gurley D, Brook J, Ma Y (1998) The risk for earlyadulthood anxiety and depressive disorders in adolescents with anxiety and depressive disorders. Arch Gen Psychiatry 55:56-64. CrossRef Medline

Roy AK, Shehzad Z, Margulies DS, Kelly AM, Uddin LQ, Gotimer K, Biswal BB, Castellanos FX, Milham MP (2009) Functional connectivity of the human amygdala using resting state fMRI. Neuroimage 45:614-626. CrossRef Medline

Said CP, Moore CD, Norman KA, Haxby JV, Todorov A (2010) Graded representations of emotional expressions in the left superior temporal sulcus. Front Syst Neurosci 4:6. CrossRef Medline

Sergerie K, Chochol C, Armony JL (2008) The role of the amygdala in emotional processing: a quantitative meta-analysis of functional neuroimaging studies. Neurosci Biobehav Rev 32:811-830. CrossRef Medline

Somerville LH, Whalen PJ (2006) Prior experience as a stimulus category confound: an example using facial expressions of emotion. Soc Cogn Affect Neurosci 1:271-274. CrossRef Medline

Talairach J, Tournoux P (1988) Co-planar stereotaxic atlas of the human brain: 3-dimensional proportional system: an approach to cerebral imaging. New York: Thieme.

Thomas KM, Drevets WC, Whalen PJ, Eccard CH, Dahl RE, Ryan ND, Casey BJ (2001) Amygdala response to facial expressions in children and adults. Biol Psychiatry 49:309-316. CrossRef Medline

Ulfig N, Setzer M, Bohl J (2003) Ontogeny of the human amygdala. Ann N Y Acad Sci 985:22-33. CrossRef Medline

Van Dijk KR, Sabuncu MR, Buckner RL (2012) The influence of head motion on intrinsic functional connectivity MRI. Neuroimage 59: 431-438. CrossRef Medline

Van Eden CG, Uylings HB (1985) Postnatal volumetric development of the prefrontal cortex in the rat. J Comp Neurol 241:268-274. CrossRef Medline

Verwer RW, Van Vulpen EH, Van Uum JF (1996) Postnatal development of amygdaloid projections to the prefrontal cortex in the rat studied with retrograde and anterograde tracers. J Comp Neurol 376:75-96. CrossRef Medline

Wager TD, Nichols TE (2003) Optimization of experimental design in fMRI: a general framework using a genetic algorithm. Neuroimage 18: 293-309. CrossRef Medline

Wager TD, Phan KL, Liberzon I, Taylor SF (2003) Valence, gender, and lateralization of functional brain anatomy in emotion: a meta-analysis of findings from neuroimaging. Neuroimage 19:513-531. CrossRef Medline

Whalen PJ, Rauch SL, Etcoff NL, McInerney SC, Lee MB, Jenike MA (1998) Masked presentations of emotional facial expressions modulate amygdala activity without explicit knowledge. J Neurosci 18:411-418. Medline

Whalen PJ, Shin LM, McInerney SC, Fischer H, Wright CI, Rauch SL (2001) A functional MRI study of human amygdala responses to facial expressions of fear versus anger. Emotion 1:70-83. CrossRef Medline

Wright CI, Fischer H, Whalen PJ, McInerney SC, Shin LM, Rauch SL (2001) Differential prefrontal cortex and amygdala habituation to repeatedly presented emotional stimuli. Neuroreport 12:379-383. CrossRef Medline

Zelazo PD, Frye D, Rapus T (1996) An age-related dissociation between knowing rules and using them. Cogn Dev 11:37-63. CrossRef 